\title{
Prediction of post-operative necrosis after mastectomy: A pilot study utilizing optical diffusion imaging spectroscopy
} Roshni Rao*1, Michel Saint-Cyr ${ }^{2}$, Aye Moe Thu Ma ${ }^{1}$, Monet Bowling1, Daniel A Hatef ${ }^{2}$, Valerie Andrews ${ }^{1}$, Xian-Jin Xie ${ }^{3}$, Theresa Zogakis ${ }^{1}$ and Rod Rohrich ${ }^{2}$

\author{
Address: ${ }^{1}$ Department of Surgery, Division of Surgical Oncology, University of Texas, Southwestern Medical Center, 5323 Harry Hines Blvd, Dallas, \\ TX 75390-9155, USA, ${ }^{2}$ Department of Plastic Surgery, University of Texas Southwestern Medical Center, 5323 Harry Hines Blvd., Dallas, TX 75390- \\ 9155, USA and ${ }^{3}$ Department of Clinical Sciences-Division of Biostatistics, University of Texas Southwestern Medical Center, 5323 Harry Hines \\ Blvd, Dallas, TX 75390-9155, USA \\ Email: Roshni Rao* - Roshni.Rao@utsouthwestern.edu; Michel Saint-Cyr - Michel.Saint-Cyr@UTSouthwestern.edu; Aye Moe \\ Thu Ma - atma@chpnet.org; Monet Bowling - mwbowlin@iupui.edu; Daniel A Hatef - dan.hatef@gmail.com; \\ Valerie Andrews - Valerie.Andrews@UTSouthwestern.edu; Xian-Jin Xie - Xian-Jin.Xie@UTSouthwestern.edu; \\ Theresa Zogakis - t.g.zogakis@att.net; Rod Rohrich - Rod.Rohrich@UTSouthwestern.edu \\ * Corresponding author
}

Published: 25 November 2009

World Journal of Surgical Oncology 2009, 7:91 doi:10.1186/1477-78|9-7-91
Received: 23 September 2009 Accepted: 25 November 2009

This article is available from: http://www.wjso.com/content/7/I/91

(c) 2009 Rao et al; licensee BioMed Central Ltd.

This is an Open Access article distributed under the terms of the Creative Commons Attribution License (http://creativecommons.org/licenses/by/2.0), which permits unrestricted use, distribution, and reproduction in any medium, provided the original work is properly cited.

\begin{abstract}
Introduction: Flap necrosis and epidermolysis occurs in 18-30\% of all mastectomies. Complications may be prevented by intra-operative detection of ischemia. Currently, no technique enables quantitative valuation of mastectomy skin perfusion. Optical Diffusion Imaging Spectroscopy (ViOptix T.Ox Tissue Oximeter) measures the ratio of oxyhemoglobin to deoxyhemoglobin over a $\mathrm{I} \times \mathrm{I} \mathrm{cm}$ area to obtain a non-invasive measurement of perfusion $\left(\mathrm{StO}_{2}\right)$.

Methods: This study evaluates the ability of ViOptix T.Ox Tissue Oximeter to predict mastectomy flap necrosis. $\mathrm{StO}_{2}$ measurements were taken at five points before and at completion of dissection in 10 patients. Data collected included: demographics, tumor size, flap length/ thickness, co-morbidities, procedure length, and wound complications.

Results: One patient experienced mastectomy skin flap necrosis. Five patients underwent immediate reconstruction, including the patient with necrosis. Statistically significant factors contributing to necrosis included reduction in medial flap $\mathrm{StO}_{2}(\mathrm{p}=0.0189)$, reduction in inferior flap $\mathrm{StO}_{2}(p=0.003)$, and flap length $(p=0.009)$.

Conclusion: $\mathrm{StO}_{2}$ reductions may be utilized to identify impaired perfusion in mastectomy skin flaps.
\end{abstract}

\section{Synopsis}

In this pilot study of ten patients, increased mastectomy flap length, a significant drop in medial and inferior $\mathrm{StO}_{2}$ measurements by Optical Diffusion Imaging Spectroscopy (ViOptix T.Ox Tissue Oximeter) intra-operatively predicted post-operative mastectomy skin flap necrosis. 


\section{Introduction}

Breast cancer is diagnosed in approximately 200,000 women in the United States every year. Surgical treatment for breast cancer involves either breast conserving surgery (BCT) or total mastectomy. Although recent studies [1] indicate that the majority of patients diagnosed with breast cancer receive $\mathrm{BCT}, 33 \%$ of patients continue to undergo mastectomy [1]. There also appears to be a significant improvement in the utilization of post-mastectomy reconstruction across the country [2]. Although the benefits of immediate reconstruction after mastectomy are well-documented [3], it has also been demonstrated that immediate reconstruction does increase the rate of postoperative wound complications [4]. Wound complications following mastectomy are estimated to be between $18-30 \%[5,6]$. Common complications include partial flap necrosis, epidermolysis and eschar formation.

Overall cosmetic outcome is highly dependent on the viability of mastectomy skin flaps. There is currently no accepted standard for evaluating skin flaps in the intraoperative setting. Techniques which are utilized include the injection of fluorescein, evaluation of "bleeding edges", and subjective assessment of capillary refill. Near Infrared Spectroscopy is a non-invasive method used to monitor blood perfusion to skin flaps. The unit of measurement is $\mathrm{StO}_{2}$. This is a measurement of the ratio of oxyhemoglobin $\left(\mathrm{HgbO}_{2}\right)$ and deoxyhemoglobin $(\mathrm{Hgb})$ in order to obtain noninvasive, real-time measurement of tissue $\mathrm{pO}_{2}$. This technique has previously been validated and is commonly used by plastic and reconstructive surgeons to assess the perfusion and viability of donor digital implants and microsurgical free tissue transfers [7-9]. The current pilot study evaluates the ability of near infrared spectroscopy to predict post-mastectomy skin flap necrosis in 10 patients.

\section{Methods}

Approval for the protocol was obtained from the Institutional Review Board at the University of Texas Southwestern Medical Center. Ten patients undergoing mastectomy at a single institution were selected for the study. Data recorded included patient age, height/weight, co-morbidities, smoking history, medical history, tumor size, pathology and stage.

\section{Tissue Oximeter}

The ViOptix T.Ox Tissue Oximeter Tissue Oximeter ${ }^{\circledast}$ made by ViOptix, Inc. (Fremont, CA) was used to obtain tissue oxygen saturation $\left(\mathrm{StO}_{2}\right)$ measurements. Near-infrared lights of $690-\mathrm{nm}$ and $830-\mathrm{nm}$ wavelengths are emitted at a scan rate of up to $40 \mathrm{~Hz}$ and are transmitted to the tissue through a special quartz fiberglass cable. The light is absorbed, scattered, and reflected in the layers of the tissue up to $10 \mathrm{~mm}$ deep, including the capillary loops and dermal plexus. The light is absorbed by biological compounds known as chromophores, whose absorption properties are oxygen-dependent. Common chromophores include hemoglobin, myoglobin, and cytochrome c oxidase. The volume of tissue under investigation is determined by the depth of near infrared light penetration $(10 \mathrm{~mm})$. The amount of light recovered from tissues is dependent on the intensity of incident light, separation of the optodes, degree of light scattering in tissues, and amount of absorption by chromophores. Since the intensity, distance between the optodes and light scattering are controlled, the changes in recovered light can be attributed to the variation in the concentration of chromophores. The recovered light is then processed by an integrated computer performing a fingerprint analysis of the spectral data. The data is then displayed in real-time, numerically, on a monitor.

\section{Patients}

A cohort of patients was selected who were undergoing mastectomy--both skin-sparing and traditional mastectomy patients were chosen to more accurately reflect the heterogeneity encountered by the practicing surgeon. Measurements were made preoperatively, and immediately after dissection at the following locations: superior mastectomy skin flap; lateral mastectomy skin flap; medial mastectomy skin flap; inferior mastectomy skin flap; and $2 \mathrm{~cm}$ inferior to the clavicle (Figure 1). Method of reconstruction, mastectomy operative time, measurements of the thickness of each skin flap, and length from clavicle to superior edge of the mastectomy skin flap were all recorded.

\section{Measurements}

Flap thickness was measured by allowing the skin to lie in a neutral position against the chest wall and then utilizing an intra-operative ruler to measure the skin flap at its most distal aspect. Flap length was defined as the superior flap length, this area was measured since this is typically the longest flap in a mastectomy. It was measured by allowing all skin to lie in a neutral position and measuring the distance, in $\mathrm{cm}$, from the edge of the superior portion of the incision at the 12 o'clock position to the clavicle, care was taken to ensure that a straight line was maintained during this measurement. All complications were noted; presence and total area of epidermolysis was noted and recorded. Patients were followed for four weeks postoperatively to estimate the area of necrosis, evaluate for wound infection, and seroma formation. De-identified data was entered into a Microsoft Excel ${ }^{\oplus}$ database. Statistical analysis was performed using Wilcoxon Rank Sum test and Student's $t$-test. 


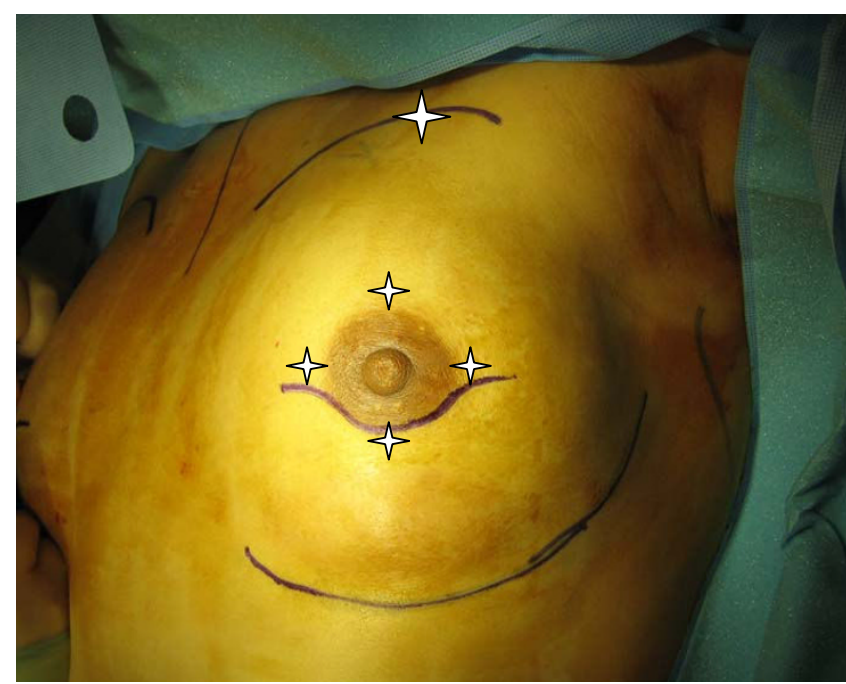

Figure I

Cardinal points of measurement pre-operatively.

\section{Results}

Of the 10 patients in this study, $1(10 \%)$ developed significant mastectomy skin flap necrosis. Measurements were obtained during the operation, the first one just prior to dissection, and the $2^{\text {nd }}$ at the completion of the mastectomy, comparisons were then performed between these numbers. Statistically significant factors predicting postop necrosis included reductions in medial $(p=0.0189)$ and inferior $(\mathrm{p}=0.003) \mathrm{StO}_{2}$ levels, and flap length $(\mathrm{p}=$ 0.009 ) (Table 1). In the patient who experienced necrosis, medial $\mathrm{StO}_{2}$ reduction was $61 \%(\mathrm{p}=0.049)$, corresponding with an absolute medial $\mathrm{StO}_{2}$ reduction of 42 points. Patients who did not have necrosis actually had an increase in their medial $\mathrm{StO}_{2}$ of $14.6 \%$, corresponding with an absolute medial $\mathrm{StO}_{2}$ increase of 6.7 points. The patient with necrosis had a $69 \%$ decrease in inferior $\mathrm{StO}_{2}$ levels, corresponding with a 65.5 point drop $(\mathrm{p}=0.003)$. Patients without necrosis demonstrated a $20 \%$ increase in inferior $\mathrm{StO}_{2}$ levels, corresponding with a 9.8 point increase in absolute $\mathrm{StO}_{2}$ levels. The patient with necrosis had a $15 \mathrm{~cm}$ flap length, as opposed to a $11.9 \mathrm{~cm}$ average flap length in the other 9 patients $(\mathrm{p}=0.009)$.

Patient demographics are displayed in Table 2 . Fifty percent of patients were African-American, $40 \%$ were Hispanic, $10 \%$ were White. The average age was 49 , average body mass index (BMI) was 27.9. There were two patients with diabetes and five with hypertension. None of the patients had chronic obstructive pulmonary disease (COPD) or admitted to smoking. Only one patient had evidence of tumor skin involvement. The stage of the primary tumor ranged from DCIS to T4D. Three patients had DCIS, and five had invasive ductal cancer. Five patients had undergone neoadjuvant chemotherapy, and one had previously received radiation to the chest wall. Average operative time was 109 minutes $(60-180 \mathrm{~min})$, a factor which was not significantly different between the two groups. The one patient with necrosis did have an expander in place, four of the patients without necrosis also had expanders, all of these patients underwent skinsparing mastectomy. There were no nipple-sparing mastectomies in this cohort. The remaining five patients did not undergo immediate reconstruction and underwent mastectomy with a standard elliptical incision. Operative time, BMI, tumor pathology, tumor size, patient age and operating surgeon were not significant factors in predicting necrosis.

The patient with $108 \mathrm{~cm}^{2}$ of necrosis (Figure 2) underwent skin-sparing mastectomy, sentinel node biopsy and immediate reconstruction with expander placement. The expander was not filled intra-operatively. This patient had uniquely significant drops in $\mathrm{StO}_{2}$ measurements postoperatively (Figure 2). This patient had full thickness necrosis in several areas of the mastectomy skin flap. She did have a personal history of Hepatitis C, sarcoidosis, and hypertension. Intraoperative fluorescein dye injection was also used to assess mastectomy skin flap viability and did indicate a possible perfusion deficit at the $2 \mathrm{o}^{\prime}$ clock position. Due to the overlying skin necrosis and consequent exposed expander, she required expander removal and skin graft two months after her mastectomy.

\section{Discussion}

One commonly used tool to evaluate mastectomy flap viability intra-operatively is the intravenous sodium fluorescein test (Wood's lamp method). This involves intravenous injection of fluorescein followed by intra-operative evaluation with a Wood's lamp. Although it has been available since 1931, its application is prone to subjective errors, and is limited to over/under reading by as much as $30 \%$ [10]. It is also a test of vascularity - not viability, and subject to changes in vascularity such as vasospasm, intravascular clotting, or alterations in the distribution of the microcirculation. Alternatively the use of infrared spectroscopy takes into account metabolic changes of the dissected tissue, and potentially allows trends to be followed for flap evaluation post-operatively.

The arterial supply of the breast is generally defined as an anastomotic plexus of vessels originating from the axillary artery, the internal mammary artery, the intercostal arteries, and lateral thoracic artery. The contribution of each individual artery and the consequences of vascular interruption are poorly understood, but the course of the nerves and vessels may be related to the ligamentous apparatus [11]. One such horizontal ligamentous suspension originates from the pectoral fascia along the $5^{\text {th }}$ rib [12]. Our finding that the decrease in perfusion from the 
Table I: Analysis of patients with and without necrosis

\begin{tabular}{|c|c|c|c|}
\hline & \multicolumn{2}{|c|}{ Necrosis } & \multirow[b]{2}{*}{ p-value } \\
\hline & Yes (I) & No (9) & \\
\hline Age & 57 & 48 & 0.278 \\
\hline Seroma & 0 & 1 & \\
\hline Infection & 0 & 1 & \\
\hline Diabetes & 0 & 2 & \\
\hline Radiation & 0 & I & \\
\hline Hypertension & 1 & 4 & \\
\hline Flap Length $(\mathrm{cm})$ & 15 & 11.9 & 0.009 \\
\hline \multicolumn{4}{|c|}{ Thickness of flap (mm) } \\
\hline Superior & 3.0 & 4.2 & 0.201 \\
\hline Inferior & 3.0 & 4.4 & 0.100 \\
\hline Lateral & 4.0 & 40 & 1.000 \\
\hline Medial & 4.0 & 4.0 & 1.000 \\
\hline \multicolumn{4}{|c|}{ Pre-operative Tissue Oxygenation (StO2) } \\
\hline Superior & 59.0 & 60.9 & 0.910 \\
\hline Inferior & 94.0 & 49.1 & 0.0017 \\
\hline Lateral & 73.5 & 58.2 & 0.371 \\
\hline Medial & 68.5 & 58.5 & 0.540 \\
\hline \multicolumn{4}{|c|}{ Post-operative Tissue Oxygenation (StO2) } \\
\hline Superior & 28 & 54.4 & 0.083 \\
\hline Inferior & 29 & 59.0 & 0.199 \\
\hline Lateral & 50 & 62.2 & .0586 \\
\hline Medial & 27 & 65.2 & 0.058 \\
\hline \multicolumn{4}{|c|}{$\begin{array}{l}\text { Changes in Tissue Oxygenation } \\
\text { StO2 percent change (absolute StO2 change) }\end{array}$} \\
\hline Superior & $-53 \%(-31.5)$ & $-5.9 \%(-6.5)$ & 0.280 \\
\hline Inferior & $-69 \%(-65.5)$ & $+20 \%(+9.8)$ & 0.003 \\
\hline Lateral & $-32 \%(-23.5)$ & $+7.17 \%(+4.1)$ & 0.145 \\
\hline Medial & $-61 \%(-42)$ & $+14.6 \%(+6.7)$ & 0.018 \\
\hline Clavicular & $+6 \%(+2)$ & $+14.6 \%(+6.8)$ & 0.850 \\
\hline
\end{tabular}

Variables analyzed, statistically significant variables are bold and italicized

inferior portion of the breast most accurately predicted post-operative epidermolysis may be supportive of this finding.

In addition, there currently does not exist any standardized method for measuring mastectomy skin flap thickness during an operation, further refinements in this technique-i.e. the use of calipers, may be helpful for future trials.

Traditionally, surgeons are careful to avoid transection of medial perforators. Consistent with this, our data demonstrate an increased likelihood of necrosis in the patient who had a significant decrease in medial $\mathrm{StO}_{2}$ measurements. This may be particularly important in those patients who undergo disruption of the medial perforators secondary to internal mammary node dissection.
Table 2: Patient Demographics

\begin{tabular}{|c|c|}
\hline Factor & $\%(n)$ \\
\hline Average Age & 49 \\
\hline \multicolumn{2}{|l|}{ Race } \\
\hline White & $10 \%(1)$ \\
\hline African American & $50 \%(5)$ \\
\hline Hispanic & $40 \%(4)$ \\
\hline \multicolumn{2}{|l|}{ Body Mass Index (BMI) } \\
\hline Average & 27.9 \\
\hline Smoking & $0 \%(0)$ \\
\hline \multicolumn{2}{|l|}{ Co-morbidities } \\
\hline Diabetes & $20 \%(2)$ \\
\hline Hypertension & $50 \%(5)$ \\
\hline COPD & $0 \%(0)$ \\
\hline \multicolumn{2}{|l|}{ Skin Involvement } \\
\hline None & $80 \%(8)$ \\
\hline Skin retraction & $10 \%(I)$ \\
\hline \multicolumn{2}{|l|}{ Clinical T Size } \\
\hline Tis & $30 \%(3)$ \\
\hline T0 & $10 \%(I)$ \\
\hline TI & $30 \%(3)$ \\
\hline $\mathrm{T} 3$ & $10 \%(1)$ \\
\hline T4A & $10 \%(1)$ \\
\hline $\mathrm{T} 4 \mathrm{D}$ & $10 \%(I)$ \\
\hline \multicolumn{2}{|l|}{ Histology } \\
\hline DCIS & $30 \%(3)$ \\
\hline Invasive Ductal & $50 \%(5)$ \\
\hline Invasive Lobular & $10 \%(1)$ \\
\hline Other & $10 \%(I)$ \\
\hline Neoadjuvant Chemo & $50 \%(5)$ \\
\hline Radiation to Chest Wall & $10 \%(10)$ \\
\hline
\end{tabular}

There are significant limitations to this study. Most notable is the small sample size. Contributions from underlying co-morbidities (coronary artery disease, diabetes) may be more readily apparent with a larger sample size. In addition, this study population was predominately a minority population; there is an under-representation of Caucasian patients. Although the ViOptix T.Ox Tissue Oximeter system has been validated in several racial groups, there may be variability in $\mathrm{StO}_{2}$ measurements between races which can only be further elucidated with a large sample size. For further studies, assuming a $10 \%$ necrosis rate, a sample of 40 patients will provide more than $90 \%$ power to detect a two standard deviation difference of the mean $\mathrm{StO}_{2}$ measures (significance level is held at 0.05 , two sided). Clearly a group of patients undergoing skin-sparing mastectomy with immediate reconstruction 


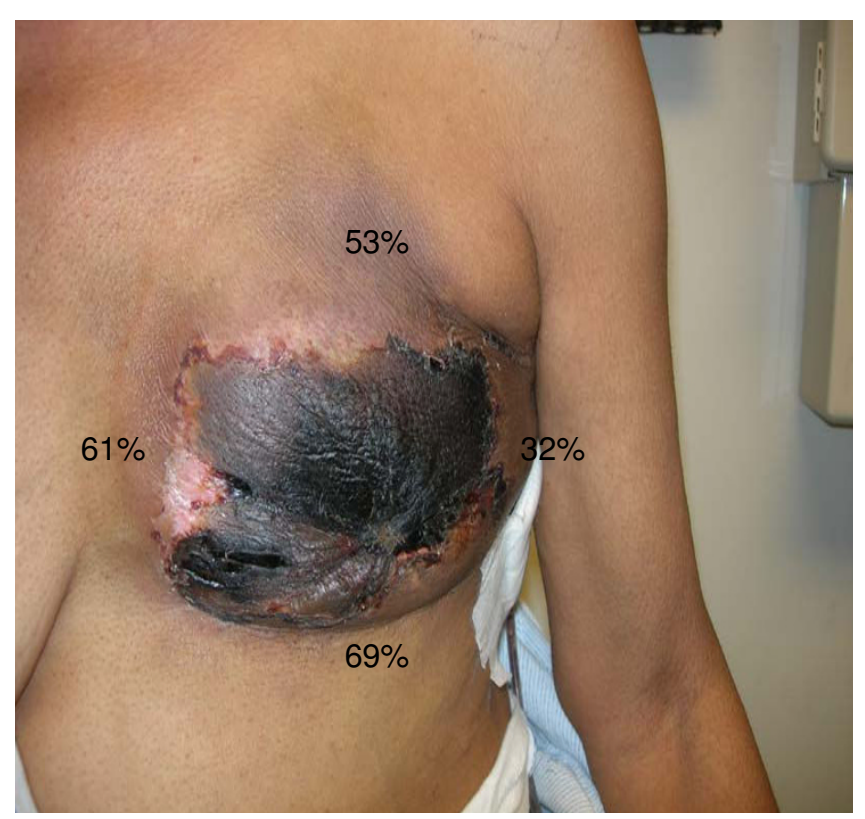

Figure 2

A patient with significant intraoperative decrease in $\mathrm{StO}_{2}$. Decreases were: $53 \%, 69 \%, 61 \%$, and $32 \%$ at superior, inferior, medial, and lateral, respectively.

would provide the most useful clinical information as these patients are more likely to have difficulties with wound healing and face the greatest consequences (implant extrusion, flap failure) from poor wound healing.

It is known that the perfusion to the subdermal plexus of the skin is controlled by the autonomic nervous system in response to variations in metabolic demands and environment. All patients in this study were stable intra-operatively. However, the actual oxygen saturation and blood pressure measurements at the time of $\mathrm{StO}_{2}$ measurement were not evaluated, the influence of these factors will be examined in future studies. The patient with necrosis had drops in $\mathrm{StO}_{2}$ measurement, which also may be an indicator of failure to compensate for injury, whereas the patients who did not have necrosis, for the most part, had increased $\mathrm{StO}_{2}$ levels after dissection, potentially indicating an ability to increase perfusion appropriately to the area of injury.

Similarly, wound healing is a complicated process. Factors contributing to or complicating the wound healing process include body habitus, age, co-morbidities, prolonged operative time, collagen disorders, infection, history of radiation exposure, immune status, and steroid use [13$15]$.
Lastly, a review of the patient response to the ViOptix T.Ox Tissue Oximeter system indicates that the patient having necrosis also had a longer flap length. This would appear to be consistent with the concept that the blood supply of longer flaps is more tenuous, likely due to the greater area of vascular disruption required when a mastectomy is performed.

\section{Conclusion}

Commonly used intraoperative methods to determine flap viability include detection of skin discoloration, wound edge bleeding and intra-operative assessment with fluorescein and a Wood's Lamp. The use of near-infrared reflection spectroscopy to monitor myocutaneous flaps has been previously validated in humans [9]. Our study indicates that ViOptix T.Ox Tissue Oximeter is a non-invasive method which may be utilized to identify impaired perfusion in mastectomy skin flaps. It could potentially add valuable information to clinical observation, and may be able to detect early vascular complications. Areas which demonstrate sub-optimal perfusion can therefore be excised intra-operatively to potentially decrease wound complications and improve cosmetic outcome, alternatively, reconstruction may also be postponed until a later date or potentially an autologous reconstruction may be considered. Further studies are planned with a larger sample size for validation, and to establish standards.

\section{Consent}

Written informed consent was obtained from the patient for publication of this case report and accompanying images. A copy of the written consent is available for review by the Editor-In-Chief of this journal.

\section{Competing interests}

The authors declare that they have no competing interests.

\section{Authors' contributions}

RR initiated this research \& enrolled patients, \& wrote the initial manuscript, MS-C designed the study, assisted with writing the manuscript \& enrolled patients, AMTM collected data and wrote portions of the manuscript, $\mathrm{MB}$ collected data, DH collected data and assisted with study design, VA enrolled patients and performed measurements, X-JX performed all statistical analysis, TZ enrolled patients and performed measurements, RR enrolled patients and assisted with manuscript writing. All authors have read and approved the final manuscript.

\section{Acknowledgements}

The authors are grateful to the invaluable assistance of our colleagues: William Brooks MD, Fiemu Nwariaku MD, Lisa Lilley NP, William Lodrigues NP, Victoria Warren RN, and Fatemah Youssefi PhD. 
Presented at the 24th Annual Miami Breast Cancer Conference, February $\left.2\right|^{\text {st }}-24^{\text {th }}, 2007$. Miami, FL.

Presented at the $9^{\text {th }}$ Annual University of Texas Southwestern Department of Surgery Surgical Research Forum, June 6, 2007. Dallas, TX.

\section{References}

I. Malin JL, Schneider EC, Epstein AM, Adams J, Emanuel EJ, Kahn KL: Results of the National Initiative for Cancer Care Quality: how can we improve the quality of cancer care in the United States? I Clin Oncol 2006, 24:626-634.

2. Christian CK, Niland J, Edge SB, Ottesen RA, Hughes ME, Theriault R, Wilson J, Hergrueter CA, Weeks JC: A multi-institutional analysis of the socioeconomic determinants of breast reconstruction: a study of the National Comprehensive Cancer Network. Ann Surg 2006, 243:24I-249.

3. Rowland JH, Desmond KA, Meyerowitz BE, Belin TR, Wyatt GE, Ganz PA: Role of breast reconstructive surgery in physical and emotional outcomes among breast cancer survivors. I Natl Cancer Inst 2000, 92: |422-| 429.

4. Mortenson MM, Schneider PD, Khatri VP, Stevenson TR, Whetzel TP, Sommerhaug EJ, Goodnight JE Jr, Bold RJ: Immediate breast reconstruction after mastectomy increases wound complications: however, initiation of adjuvant chemotherapy is not delayed. Arch Surg 2004, I 39:988-991.

5. Margulies AG, Hochberg J, Kepple J, Henry-Tillman RS, Westbrook K, Klimberg VS: Total skin-sparing mastectomy without preservation of the nipple-areola complex. Am J Surg 2005, I 90:907-9|2.

6. Garwood ER, Moore D, Ewing C, Hwang ES, Alvarado M, Foster RD, Esserman LJ: Total skin-sparing mastectomy: complications and local recurrence rates in 2 cohorts of patients. Ann Surg 2009, 249:26-32.

7. Scheufler O, Exner K, Andresen R: Investigation of TRAM flap oxygenation and perfusion by near-infrared reflection spectroscopy and color-coded duplex sonography. Plast Reconstr Surg 2004, I | 3: |4|-| 52. discussion I53-|45

8. Stranc MF, Sowa MG, Abdulrauf B, Mantsch HH: Assessment of tissue viability using near-infrared spectroscopy. Br J Plast Surg |998, 5 |:210-217.

9. Mancini DM, Bolinger L, Li H, Kendrick K, Chance B, Wilson JR: Validation of near-infrared spectroscopy in humans. J Appl Physiol 1994, 77:2740-2747.

10. Myers B, Donovan W: An evaluation of eight methods of using fluorescein to predict the viability of skin flaps in the pig. Plast Reconstr Surg 1985, 75:245-250.

II. Wuringer E, Mader N, Posch E, Holle J: Nerve and vessel supplying ligamentous suspension of the mammary gland. Plast Reconstr Surg 1998, I01:1486-1493.

12. Wueringer $E$, Tschabitscher $M$ : New aspects of the topographical anatomy of the mammary gland regarding its neurovascular supply along a regular ligamentous suspension. Eur J Morphol 2002, 40: I8I-189.

13. Cruse PJ, Foord R: A five-year prospective study of 23,649 surgical wounds. Arch Surg 1973, 107:206-210.

14. Cruse PJ, Foord R: The epidemiology of wound infection. A I0year prospective study of $\mathbf{6 2 , 9 3 9}$ wounds. Surg Clin North Am 1980, 60:27-40.

15. Nandi PL, Soundara Rajan S, Mak KC, Chan SC, So YP: Surgical wound infection. Hong Kong Med J 1999, 5:82-86.

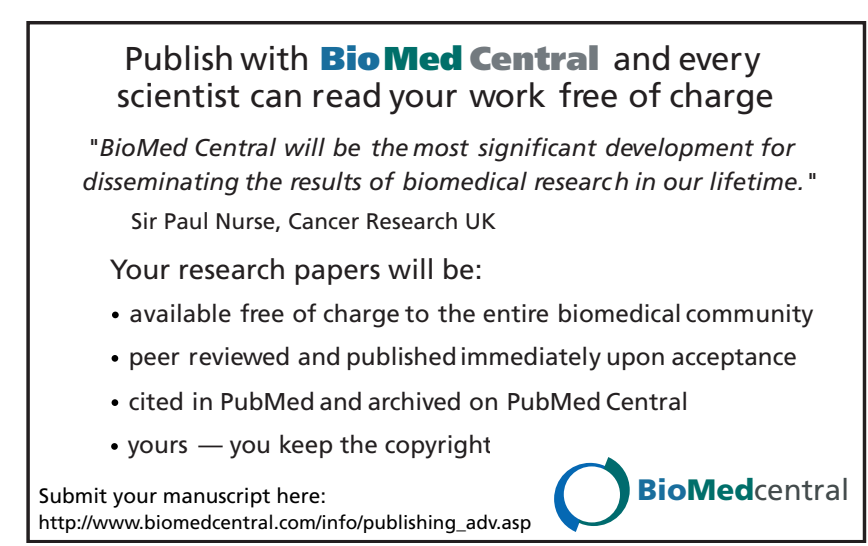

